\title{
OPINIÃO DOS PROFISSIONAIS DA SAÚDE EM RELAÇÃO À DOAÇÃO DE ÓRGÃOS E TECIDOS PARA TRANSPLANTE NO ANO DE 2009 - SANTA CASA DE BELO HORIZONTE/MG
}

\author{
Attitude os health professionals on organ and tissue donation for transplants along 2009 - \\ Hospital Santa Casa de Belo Horizonte
}

Walter Antônio Pereira', Denise Magalhães Rochido Arruda', Rachel Capanema Ferreira Mendonça', João Paulo Amaral Haddad²

\begin{abstract}
RESUMO
Objetivo: Este estudo se propõe avaliar o nível de conhecimento dos profissionais do Grupo Santa Casa de Belo Horizonte sobre vários aspectos relacionados à doação de órgãos e tecidos para transplante. Participaram deste estudo tanto profissionais que trabalham diretamente na assistência aos pacientes quanto aqueles da área administrativa e de estrutura de apoio, pois acreditamos que todos podem ser multiplicadores do conhecimento sobre o tema em sua área de atuação. Método: Foram distribuídos 2000 (dois mil) questionários com questões fechadas aos profissionais de vários segmentos, buscando homogeneizar a amostra, abordando várias questões a respeito da doação de órgãos e tecidos e dados pessoais em forma de pesquisa de opinião. Recebemos 830 questionários devidamente preenchidos, que foram digitados e processados no programa estatístico EPIDATA e EPIINFO, e avaliados pelo qui-quadrado. Resultado: Avaliamos através dos questionários que $91 \%$ dos funcionários são favoráveis à doação de órgãos e tecidos; 91,14 \% são mulheres; 49,51\% deles têm doadores na família; $51,56 \%$ das pessoas comunicaram sua opinião a respeito da doação de órgãos aos familiares. Quanto à escolaridade: 77,65\% das pessoas que responderam possuem ensino fundamental e 91,57\% ensino médio. Conclusão: Avaliamos que grande parte dos profissionais do Grupo Santa Casa de Belo Horizonte estão bem orientados/informados sobre o tema abordado, além de demonstrar interesse em participar de capacitações e palestras. Através daquela pesquisa, será possível trabalhar de maneira direcionada às dúvidas, além de divulgar e incentivar a doação de órgãos e tecidos entre profissionais da área da saúde e também junto à população leiga, visando aumentar o número de doadores efetivos, a captação de órgãos e redução da lista de espera por um transplante.
\end{abstract}

Descritores: Doação de Órgão, Profissional da Saúde, Conhecimento.

\footnotetext{
Instituição:

1 Centro de Transplantes da Santa Casa de Belo Horizonte, Belo Horizonte/MG

2 Escola de Veterinária da Universidade Federal de Minas Gerais, Belo Horizonte/MG
}

Correspondência:

Walter Antonio Pereira

Santa Casa de Belo Horizonte - Centro de Transplantes

Av. Francisco Sales, 1.111 - Santa Efigênia - CEP 30.150-221 - Belo Horizonte/MG - Brasil

Tel: (31) 3238-8529

E-mail:wpereira@medicina.ufmg.br.

Recebido em: 19.08 .2009

Aceito em: 23.09.2009

\section{INTRODUÇÃO}

Transplante é um procedimento terapêutico bem estabelecido ${ }^{1}$ e que vem apresentando progressos em seus resultados, principalmente nos últimos trinta anos. Diretamente associado ao desenvolvimento tecnológico e científico ${ }^{2}$, ele vem ganhando credibilidade como intervenção terapêutica eficaz em pacientes com doenças terminais. ${ }^{3}$

De maneira geral, podemos dizer que há três tipos de transplantes: o autotransplante, o intervivos e o de doador falecido.

A doação de enxertos de doador falecido necessita de um trabalho permanente de conscientização junto à população e profissionais da área da saúde sobre a importância e aspectos relacionados à doação. Apesar das falhas na infra-estrutura hospitalar e no número reduzido de profissionais qualificados em transplantes em nosso meio, a informação da população a respeito do tema pode trazer como consequência imediata a melhoria do nosso índice de doadores.

Esse aumento já vem ocorrendo na média nacional, sendo que o Brasil alcançou 8,6 doadores/pmp em 2008, em vários estados ultrapassando os 10 doadores/pmp. ${ }^{4}$ 
Dentre os fatores que contribuem para a negativa familiar na doação de órgãos para transplantes, podemos destacar também aqueles relacionados aos mitos e fantasias da população. Nesse contexto, o conhecimento e posicionamento dos profissionais da Instituição hospitalar são importantes para o processo, ${ }^{5}$ oferecendo subsídios para planejar e executar ações que visem maior conhecimento sobre o tema e consequente elevação do número de pessoas sensíveis à doação de órgãos e tecidos.

\section{MÉTODO}

Esta pesquisa foi realizada no Grupo Santa Casa de Belo Horizonte, um dos maiores hospitais do Estado de Minas Gerais e que mais atende pacientes da rede pública no Estado.

O projeto foi aprovado pelo Comitê de Ética e Pesquisa - CEP da Santa Casa de Belo Horizonte.

Foram utilizados questionários com questões fechadas, conforme anexo, abordando várias questões a respeito da doação de órgãos e tecidos, além de dados pessoais em forma de pesquisa de opinião. Um total de 2.000 (dois mil) questionários foi entregue aos profissionais do Grupo Santa Casa entre vários segmentos, buscando homogeneizar a amostra.

O Termo de Consentimento Livre e Esclarecido constou do corpo do questionário, conforme apresentado ao CEP.

Foram devolvidos devidamente preenchidos 830 questionários, os quais foram digitados e processados no programa estatístico EPIDATA e EPIINFO, e avaliados pelo qui-quadrado.

\section{RESULTADOS}

Na média geral, 91\% dos funcionários são favoráveis à doação de órgãos e tecidos, enquanto $9 \%$ mostraram-se contra a doação.

Dentre os favoráveis à doação, 91,14 \% eram mulheres e 91,77\%, homens; $94,35 \%$ dos solteiros e $88,85 \%$ dos casados também se manifestaram a favor da doação de órgãos.

Quanto à escolaridade, $77,65 \%$ das pessoas com ensino fundamental, 91,57\% com ensino médio e 95,40\% das pessoas que possuem ensino superior são a favor da doação. Dentre os mestres e doutores, observamos $72,72 \%$ de doação.

Observando-se as faixas etárias, 94,04\% das pessoas entre $18 \mathrm{e}$ 25 anos; 93,46\% entre 26 e 35 anos; 86,95\% entre 36 e 45 anos são a favor da doação de órgãos e tecidos.

Dentre os que aceitariam um órgão se precisasse, 94,49\% são a favor da doação de órgãos.

Entre as pessoas que responderam à entrevista, 49,51\% deles têm doadores na família e $51,56 \%$ das pessoas comunicaram sua opinião a respeito de doação de órgãos aos familiares.

No que diz respeito à morte encefálica, 88,67\% dos entrevistados responderam adequadamente sobre o que é a morte encefálica; $82,16 \%$ dos entrevistados acreditam que o corpo dos doadores falecidos não sofre deformações (Figura 1).

\section{DISCUSSÃO}

Os resultados demonstraram bom conhecimento entre os profissionais do Grupo, independentemente da área de atuação. Também demonstraram necessidade de trabalhar questões como:
Figura 1

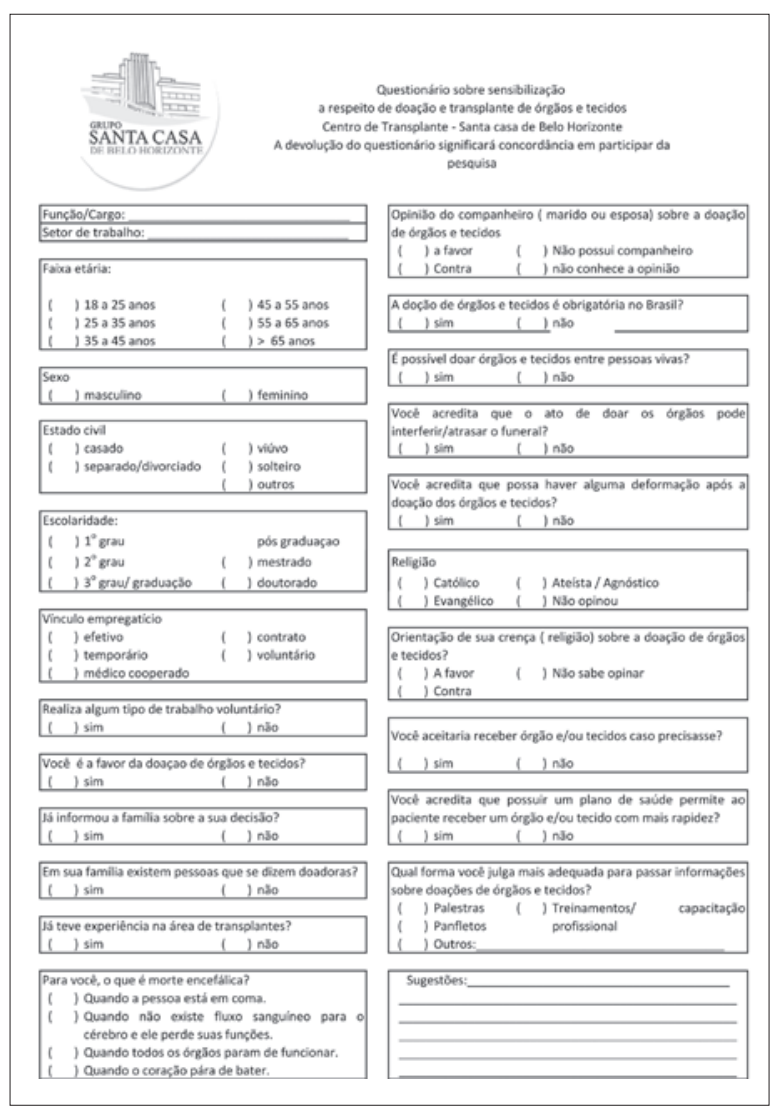

possibilidade de deformação do corpo, relação da doação com possível atraso no funeral, possibilidade do plano de saúde agilizar o transplante, entre outras.

Muitas dessas questões envolvem fantasias e mitos sobre doação de órgãos e a forma como eles são retirados, uma vez que poucos já presenciaram uma retirada de órgão para perceber a complexidade e o compromisso do procedimento e de todas as equipes envolvidas no ato cirúrgico.

Sobre a escolaridade, observamos que à medida em que a pessoa tem maior grau de instrução, maior é seu grau de conhecimento sobre doação de órgãos, tendo em nossa pesquisa a exceção de pessoas com mestrado e doutorado que demonstraram menor percentual até do que funcionários de nível fundamental.

A maioria dos entrevistados acredita que a religião é a favor da doação (58,4\%), mas o número de pessoas que não opinou também foi expressivo (36,02\%), o que pode indicar desinformação sobre o assunto.

Sobre a informação à família, apenas 428 (51,56\%) comunicaram sua vontade de ser doador, o que enfatiza a necessidade de informação sobre o tema, já que só existirão doadores no Brasil a partir do momento em que os familiares autorizarem a doação de órgãos e tecidos.

Como exemplo dos mitos e percepções fantasiosas que podem interferir na decisão de doar, existe o medo do tráfico de órgãos e a antiga doação presumida. É importante divulgar que a doação 
registrada em carteira de identidade já não vigora mais, sendo a família a única responsável pela autorização da doação.

\section{CONCLUSÃO}

Avaliamos que grande parte dos profissionais do Grupo Santa Casa de Belo Horizonte estão bem orientadas/informadas sobre o tema abordado, além de demonstrar interesse em participar de capacitações e palestras.
Através desta pesquisa será possível trabalhar as dúvidas, além de divulgar e incentivar a doação de órgãos e tecidos entre profissionais da área da saúde e também junto à população leiga, visando o aumento do número de doadores efetivos, captação de órgãos e redução da lista de espera por um transplante.

O êxito do processo relacionado à doação deve-se ao trabalho de toda a equipe, com uma interação multiprofissional e contínua, onde todos exercem papel único e fundamental. ${ }^{6}$

\section{ABSTRACT}

Purpose: This study aims to assess the level of the knowledge of the professionals at Santa Casa de Belo Horizonte on several aspects related to the organ and tissue donation for transplants. The study included both professionals directly working in the patient care asnd the ones from the administrative and support structure, since we believe that everyone might be a knowledge multiplier on this subject in such area of operation. Methods: It was distributed 2000 (two thousand) questionnaires containing closed questions to professionals of several segments, trying to get a mixed sampling addressing several issues concerning the organ and tissue donation as well as personal data in the form of the survey. 830 questionnaires duly completed were received, which were inserted and processed using the Statistical EpiData and EPIINFO software; they was evaluated by chi-square. Result: Through the questionnaires, we evaluated that $91 \%$ of all employees are pro-organ and tissue donation, being $91.14 \%$ females and $49.51 \%$ have donors in their family; $51.56 \%$ of them reported their opinion about the organ donation to family members. As to education: $77.65 \%$ of them who answered the questionnaire had primary education and $91.57 \%$ had high school. Conclusion: We evaluated that most of the Santa Casa de Belo Horizonte health professionals are well oriented/informed as to the subject, and they showed interest in participating of trainings and lectures. Through the research, it will be possible to work aiming targeted doubts to disseminate and encourage the organ and tissue donation among health professionals, and also among the population in general, in order to increase the amount of actual donors, the organ procurement and decreasing the waiting list for transplants.

Keywords: Organ Donation, Health Professional, Knowledge.

\section{REFERÊNCIAS}

1. Cintra V, Sanna M.C. Transformações na administração em enfermagem no suporte aos transplantes no Brasil. Rev. Bras. Enferm, Brasília, v. 58, n. 1, Fev. 2005. Disponível em http://www.scielo.br/scielo.php?script=sci_arttext\&pid=S0034$71672005000100015 \& l n g=p t \& n r m=$ iso. Acesso em 02 Abr./2009.

2. Schirmer J, Leite R.F, Roza B.A, et al. Doação de órgãos e tecidos: o que sabem os estudantes do ensino médio? Rev. Einstein. 2007; 5(3): 213-219. Disponível em: http:// apps.einstein.br/revista/arquivos/PDF/423-einstein $\% 205 \% 203 \% 201 \% 20$ online $\% 20$ artigo\%20portugues213-219p.pdf. Acesso em 09 Abr./2009.

3. Garcia V.D. A política de transplantes no Brasil. Revista da AMRIGS, Porto Alegre, 50 (4): 313-320, out - dez. 2006. Disponível em: http://www.amrigs.org. br/revista/50-04/aesp01.pdf. Acesso em 09 Abr./2009.
4. Associação Brasileira de Transplante de Órgãos. RBT - Registro Brasileiro de Transplantes. Ano XV, nº.2, jan./jun. 2009. Disponível em: http://www. abto.org.br/abtov02/portugues/profissionais/home/home.aspx. Acesso em Abr./2009.

5. Rios A, Martinez-Alarcon L, Parrila P, et al. Health assistants faced with cadaveric organ donation in a hospital with a solid organ transplant program. Transplant International, Journal compilation 2008 European Society for Organ transplantation. 22 (2009) 360-362.

6. Frutos M.A. Conscientización para La donatión. Nefrología 1999; 19:288. Disponível em: http://www.revistanefrologia.com/mostrarfile.asp?ID=624. Acesso em 09 de Abr./2009. 